\title{
Estudio de las medidas de protección en los casos de Violencia contra la Mujer en el Primer Juzgado de Familia de Tarapoto 2017-2018
}

\section{Study of protection measures in cases of violence against women in the First Family Court Tarapoto 2017-2018}

\author{
Mondragón Carrasco, Esthefany ${ }^{1[0000-0002-7932-5793]} \&$ Siaden \\ Valdivieso, José Roberto ${ }^{1[0000-0001-5659-0992]}$ \\ ${ }^{1}$ Universidad Nacional de San Martín, Tarapoto, Perú \\ emondragonealumno.unsm.edu.pe
}

Resumen. La presente investigación, tuvo como objetivo principal analizar la relación entre las medidas de protección frente a los casos de violencia contra la mujer en el Primer Juzgado de Familia Tarapoto 2017-2018. El tipo de investigación fue básica con enfoque cuantitativo, de nivel descriptivo y diseño no experimental, la muestra estuvo conformada por 59 casos por violencia contra la mujer, para la recolección de datos se empleó como técnica el análisis documental y la entrevista, para la cual se emplearon como instrumentos la guía de análisis documental y la guía de entrevista. Llegando a concluir que se evidencia la relación significativa entre las variables en estudio, por lo tanto, se acepta la hipótesis de la investigación, asimismo tras el cálculo del coeficiente determinante se determinó que las medidas de protección influyeron en un $80 \%$ frente a los casos de violencia contra la mujer.

Palabras clave: Medidas de protección, violencia física, violencia psicológica, Violencia sexual.

Citar como: Mondragón Carrasco, E. \& Siaden Valdivieso, J. R. (2021). Estudio de las medidas de protección en los casos de Violencia contra la Mujer en el Primer Juzgado de Familia de Tarapoto 20172018. Revista Científica Ratio Iure, 1(2), 76-84. https://doi.org/10.51252/rc ri.v1i2.200

Recibido: 22/05/2021

Aceptado: 27/06/2021

Publicado: 28/07/2021

\begin{abstract}
The present research entitled "Study of protection measures in cases of violence against women in the First Family Court Tarapoto 2017 2018", had as main objective the analysis of the relationship between protection measures regarding cases of violence against women in the First Family Court Tarapoto 2017 - 2018. It was a basic research with a quantitative approach, descriptive level and non-experimental design; the sample consisted of 59 cases of violence against women presented to the First Family Court of Tarapoto 2017 - 2018, the Judge and Prosecutor of the Court, for data collection the technique of documentary analysis and the interview were used, for which the documentary analysis guide and the interview guide were used as instruments. It was concluded that a significant relationship between the variables under study is evidenced, since the correlational statistics shows a value of (0.895), with an acceptable bilateral significance whose value was (0.000), which indicates a considerable positive correlation, therefore, the hypothesis of the re-search is accepted. By the way, after the calculation of the determinant coefficient it was determined that the protection measures influenced $80 \%$ of the cases of violence against women.
\end{abstract}

Keywords: Physical violence, protective measures, psychological violence, sexual violence. 


\section{$1 \quad$ Introducción}

La protección de la mujer en los últimos años ha venido aumentado debido al incremento de violencia que se da contra la misma, por ello es considerado un tema amplio y de suma importancia en todo el mundo.

En un entorno internacional, Las Naciones Unidas, dan a conocer que la violencia contra las mujeres afecta a todas en el mundo, causando daños a la salud, disfrute sexual y reproductiva, donde se ve el arduo sufrimiento físico y psicológico para las mujeres. Asimismo, los estudios realizados por el mismo afirman que una de cada tres mujeres en un 35.6\% denuncian casos de violencia física o sexual por su pareja, $38 \%$ de las mujeres son víctimas de asesinato, $42 \%$ experimentaron violencia y salieron lesionadas y el $7.2 \%$ tuvieron violencia sexual, violando de esa manera los derechos de las mismas. En Uruguay se enfatizan en la prevención y protección de las víctimas a través de un proyecto presentando medidas de protección especiales para las mujeres, estas medidas se encuentran a disposición, sin embargo, no son supervisadas de tal manera que son violadas por los agresores quienes incumplen y por ende se incrementa la violencia contra ellas causando más muertes y daños (Naciones Unidas, 2015).

En el Perú, la violencia contra la mujer es un tema de todos los días, reflejado en las noticias nacionales, cada vez son más los casos de violencia que viven las mujeres peruanas, donde en su mayoría, el hombre es el principal agresor, perdiendo el respeto hacia ella por el hecho de ser mujer, casos donde hubo violación, golpes o acoso, pudieron haberla tocado en un transporte, o el sujeto que la lastimo salió libre de cargos o lo más denigrante terminar en un cilindro repleta de cemento.(Sugobono, 2019).

Asimismo, el ex Ministro del Interior Carlos Morán, ante estos casos de Violencia contra la mujer sugirió implementar tecnología con el fin de reducir estos actos a nivel nacional como grilletes electrónicos que puedan alertar la cercanía del agresor con su víctima y la policía nacional pueda actuar con total prontitud, además de ello dio a conocer que en Perú existen más de 41 mil medidas de protección, pero lamentablemente no pueden ser atendidas por la policía (Diario Correo, 2018). En otro contexto el servicio gratuito de Línea 100 en donde brindan orientación a mujeres con casos de violencia se vieron reflejados el incremento de llamadas en un 93\% (50951 llamadas) de las cuales $74 \%$ fueron realizadas por mujeres, en su mayoría provenientes de Lima (55.1\%), reportando casos de violencia física, psicológica o sexual. La violencia contra la mujer aumenta día tras día y es algo que aún no se puede erradicar (Diario el Comercio, 2019).

En nuestra región, la corte Superior de Justicia de San Martín, tiene a disposición un juzgado especializado de familia que se encuentra en la Provincia de San Martin - Tarapoto, este presenta grandes cifras de casos por violencia contra la mujer, donde las medidas de protección prescritas 
en la Ley $\mathrm{N}^{\circ} 30364$ no parecen ser eficaces ni las más favorables para prevenir estos casos, los casos registrados indican que el agresor no es retirado totalmente del domicilio de la víctima, asimismo este sigue teniendo contacto y es imponente, además se carece de un lugar donde se pue-da ubicar en casos de emergencia a la víctima, el tratamiento psicológico brindado poco ayuda a las víctimas, quienes se aferran a seguir teniendo contacto con su agresor, pese a las denuncias registradas en la policía nacional se sigue incrementado la muerte de muchas mujeres en la localidad, por todo ello se ejecutó esta investigación a fin de realizar el Estudio de las medidas de protección en los casos de violencia contra la mujer en el Primer Juzgado de Familia Tarapoto $2017-2018$.

De acuerdo a la realidad estudiada se formula como problema general la interrogante ¿Cómo se relaciona las medidas de protección frente a los casos de violencia contra la mujer en el Primer Juzgado de Familia Tarapoto 2017 - 2018?, y como problemas específicos se planteó las interrogantes ¿Cómo es la eficacia de las medidas de protección brindadas frente a los casos de violencia contra la mujer en el Primer Juzgado de Familia Tarapoto 2017 - 2018?, y ¿ Cuáles son los casos de violencia contra la mujer en el Primer Juzgado de Familia Tarapoto 2017 - 2018?, el mismo que permitió plantear como objetivos general analizar la relación entre las medidas de protección frente a los casos de violencia contra la mujer en el Primer Juzgado de Familia Tarapoto 2017 -2018. Y como objetivos específicos se planteó: Evaluar la eficacia de las medidas de protección brindadas frente a los casos de violencia contra la mujer en el Primer Juzgado de Familia Tarapoto 2017 - 2018, y determinar los principales tipos de violencia contra la mujer en el Primer Juzgado de Familia Tarapoto 2017 - 2018. Teniendo como hipótesis general la siguiente afirmación: H1: Las medidas de protección frente a los casos de violencia contra la mujer en el Primer Juzgado de Familia Tarapoto 2017 - 2018 se relaciona significativamente.

\section{Materiales y Métodos}

Se utilizaron dos técnicas de recolección de datos como: Análisis documental que es una técnica que se basa en el estudio de un documento, independientemente de su soporte, esta técnica nos permitió realizar búsquedas retrospectivas y recopilar lo que se necesitó y la entrevista que nos permitió recopilar información respecto a la percepción que tiene sobre un tema específico.

Se tuvo en cuenta como instrumentos de recolección de datos la guía de análisis documental y la guía de entrevista lo que permitió diseñar un modelo de recolección de datos a criterio del investigador que permitió analizar la variable del estudio y recopilar información por medio de una serie de preguntas formuladas, cuyas respuestas son abiertas. En tal sentido, la presente guía de entrevista está constituida por 5 interrogantes relacionadas con las medidas de protección dictadas por los casos de violencia contra la mujer, las mismas que serán respondidas por el Juez y Fiscal del Primer Juzgado de Familia Tarapoto, 2017-2018. 
Con la finalidad de validar los instrumentos que fueron aplicados a la muestra seleccionada fue esencial solicitar la participación de los expertos en materia de investigación, los mismos que fueron seleccionados en función a la materia en la cual se encuentran especializados de tal manera que se puedan emitir sus opiniones considerando ciertos criterios específicos y así garantizar la coherencia y congruencia de los mismos con el propósito de que puedan evaluar las medidas de protección y la violencia contra la mujer en el Primer Juzgado de Familia Tarapoto 2017 - 2018. En tal sentido, los expertos encargados de validar los instrumentos fueron: Jorge Luis Miranda Bautista, Heidegger Mendoza Ramírez y Fernando Manuel Saavedra Sosa.

El tipo de investigación fue básica con enfoque cuantitativo, de nivel descriptivo y diseño no experimental, la muestra estuvo conformada por 59 casos por violencia contra la mujer.

\section{Resultados y discusiones}

Respecto a la eficacia de las medidas de protección brindadas en los casos de violencia contra la mujer en el Primer Juzgado de Familia Tarapoto correspondiente a los años 2017 y 2018; se puede reconocer que, de acuerdo al análisis efectuado a los 59 casos objeto en estudio, se aplicaron las medidas de protección tipificadas en el Art.22 de la Ley 30364, permitiendo reconocerse de esta manera que existe un alto nivel de eficacia en las medidas de protección pues el Juez del Primer Juzgado de Familia Tarapoto ha cumplido con los plazos señalados para solicitar las me-didas de protección a favor del agraviado.

Tabla 1

Medidas de protección brindadas frente a los casos de violencia, 2017-2018.

\begin{tabular}{lcccc}
\multicolumn{1}{c}{ Medidas de protección } & $\begin{array}{c}\mathbf{2 0 1 7} \\
\mathbf{N}^{\circ} \text { Casos }\end{array}$ & $\mathbf{\%}$ & $\mathbf{2 0 1 8}$ & $\mathbf{N}^{\circ}$ casos \\
\hline Retiro del agresor del domicilio & 2 & $3 \%$ & 1 & $2 \%$ \\
Impedimento de acercamiento & 13 & $22 \%$ & 16 & $27 \%$ \\
Prohibición de comunicación & 3 & $5 \%$ & 3 & $5 \%$ \\
Prohibición de tenencia de arma & 0 & $0 \%$ & 0 & $0 \%$ \\
Inventario sobre los bienes & 0 & $0 \%$ & 0 & $0 \%$ \\
Asignación económica & 2 & $3 \%$ & 1 & $2 \%$ \\
Prohibición de enajenación de bienes & 0 & $0 \%$ & 0 & $0 \%$ \\
Prohibición de retiro de niños & 1 & $2 \%$ & 0 & $0 \%$ \\
Tratamiento terapéutico al agresor & 27 & $46 \%$ & 27 & $46 \%$ \\
Tratamiento psicológico a la victima & 32 & $54 \%$ & 27 & $46 \%$ \\
Albergue de la victima & 0 & $0 \%$ & 0 & $0 \%$ \\
Otros requeridos & 32 & $54 \%$ & 27 & $46 \%$ \\
\hline
\end{tabular}




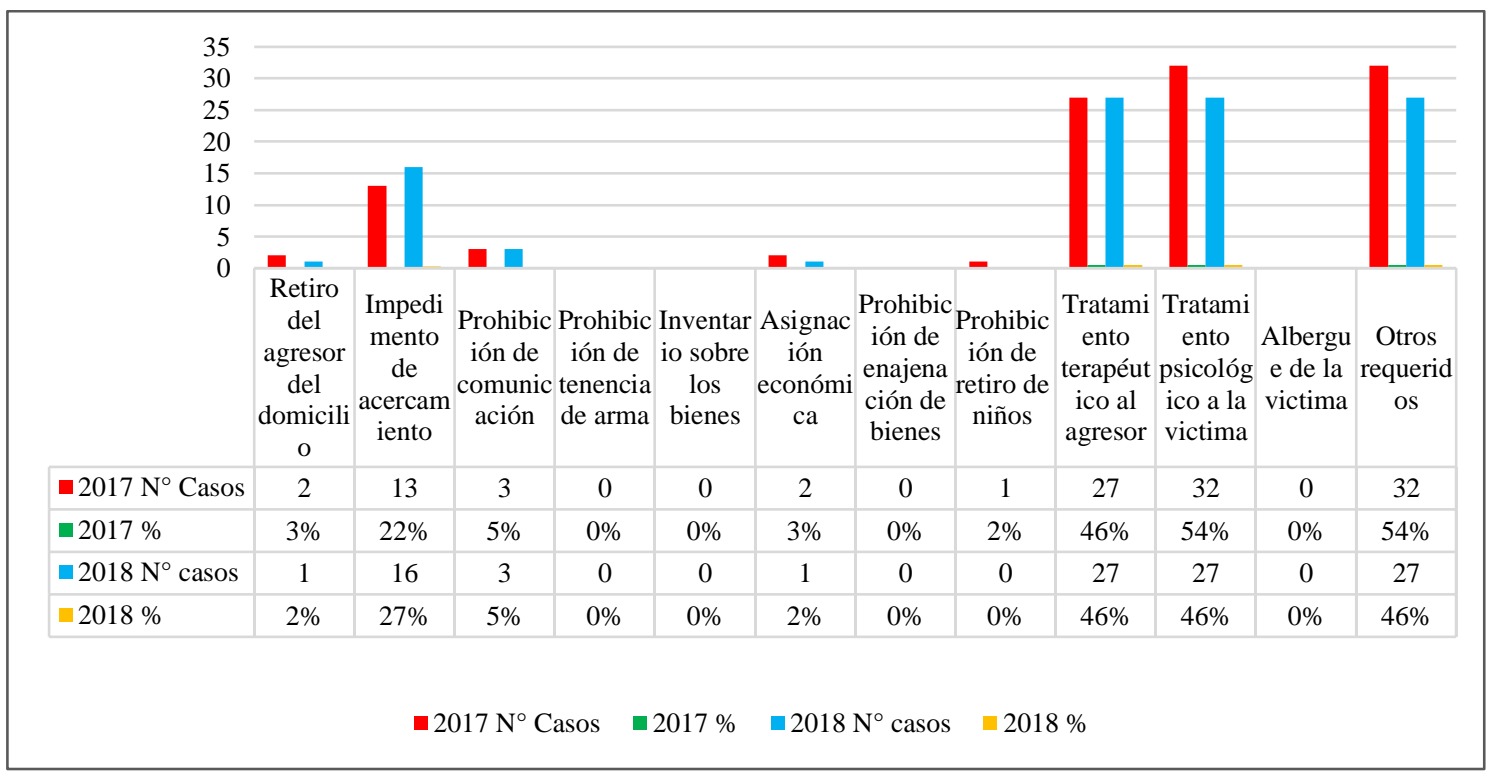

Figura 1. Medidas de protección frente a los casos de violencia, 2017 y 2018.

Se evidenció que los principales tipos de violencia contra la mujer evidenciados en las denuncias presentadas ante el Primer Juzgado de Familia Tarapoto durante los periodos 2017 y 2018, fueron la violencia física, psicológica, sexual y económica, teniendo de este modo que, en el 2017 se presentaron 21 casos de violencia física, asimismo se presentaron 27 casos de violencia psicológica, por otro lado, se evidenció que se presentó 1 caso de violencia sexual y 1 caso de violencia económica. En cuanto al periodo 2018, se evidenció que se presentaron 13 casos de violencia física, asimismo se constató que se registraron 24 casos de violencia psicológica y 1 casos de violencia económica.

Tabla 2

Tipos de violencia contra la mujer según los casos analizados, 2017 y 2018

\begin{tabular}{lcccc}
\multicolumn{1}{c}{ Tipos de violencia } & \multicolumn{2}{c}{$\mathbf{2 0 1 7}$} & \multicolumn{2}{c}{$\mathbf{2 0 1 8}$} \\
& $\begin{array}{c}\mathbf{N}^{\circ} \mathbf{d e} \\
\mathbf{c a s o s}\end{array}$ & $\mathbf{\%}$ & $\begin{array}{c}\mathbf{N}^{\circ} \mathbf{d e} \\
\text { casos }\end{array}$ & $\mathbf{\%}$ \\
\hline Violencia física & 21 & $36 \%$ & 13 & $22 \%$ \\
Violencia psicológica & 27 & $46 \%$ & 24 & $41 \%$ \\
Violencia sexual & 1 & $2 \%$ & 0 & $0 \%$ \\
Violencia económica o patrimonial & 1 & $2 \%$ & 1 & $2 \%$ \\
\hline
\end{tabular}




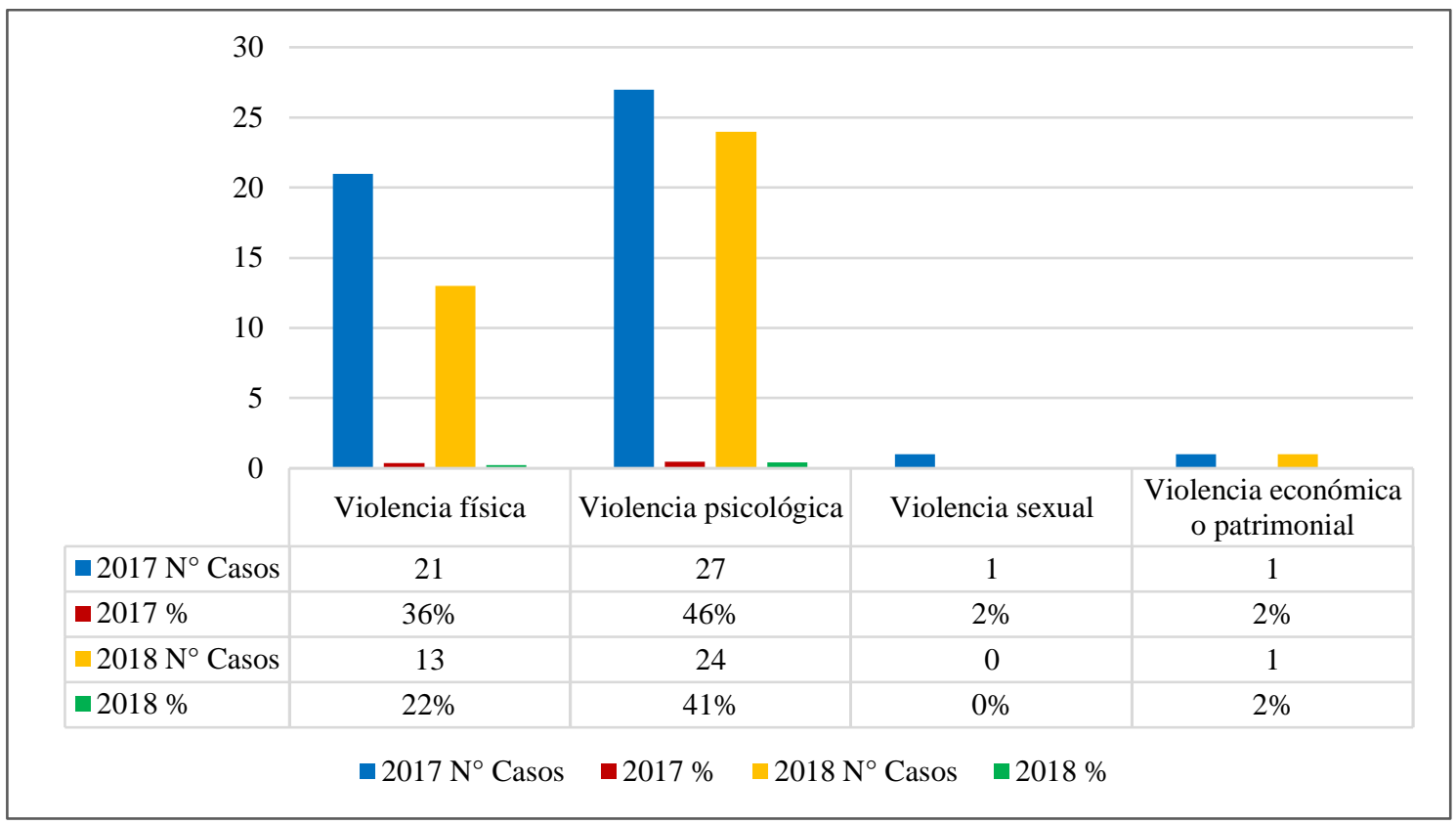

Figura 2. Tipos de violencia contra la mujer presentados durante el 2017 y 2018.

Tras el cálculo del coeficiente determinante se determinó que las medidas de protección influyeron en un $80 \%$ frente a los casos de violencia contra la mujer, en efecto es conveniente asumir que existe una correlación lineal entre las variables en estudio del presente trabajo de investigación.

Tabla 3

Análisis de las medidas de protección frente a los casos de violencia.

\begin{tabular}{llll}
\hline & & $\begin{array}{l}\text { Medidas de } \\
\text { protección }\end{array}$ & $\begin{array}{l}\text { Violencia } \\
\text { contra la mujer }\end{array}$ \\
\hline Medidas de & Correlación de Pearson & 1 & $0.895^{* *}$ \\
protección & Sig. Bilateral & & 0.000 \\
& $\mathrm{~N}$ & 16 & 16 \\
Violencia & Correlación de Pearson & $0.895^{* *}$ & 1 \\
contra la mujer & Sig. Bilateral & 0.000 & \\
& $\mathrm{~N}$ & 16 & 16 \\
\hline
\end{tabular}

Respuestas de las entrevistas relacionadas con las medidas de protección dictadas por los casos de violencia contra la mujer, las mismas que fueron respondidas por el Juez y Fiscal de Familia Tarapoto.

Entrevista realizada al Juez Titular:

1. Son medidas que tienen como objetivo proteger y resguardar la integridad personal y el patrimonio de la víctima de violencia, así como a su entorno familiar, pero algunas de ellas no se encuadran a la realidad y formas de violencia en las diferentes partes del Perú, además, debido a las limitaciones, no cumplen con su finalidad.

2. Existen muchos motivos: Por la esperanza de que el agresor cambiará de actitud, por falta de dinero para apersonarse a denunciar, por desconocimiento de sus derechos, por presión 
familiar para no efectuar la denuncia a la parte agresora, por temor a quedarse desamparadas al depender económicamente del agresor, etc.

3. No necesariamente, muchas veces es suficiente la declaración de la víctima y el resultado de la ficha de valoración de riesgo, cuando generalmente éste arroja RIESGO SEVERO, y depende mucho de cómo sucedieron los hechos, si hubo amenaza de muerte, si portaban armas y otros factores.

4. No tenemos una estadística precisa al respecto, por cuanto se encarga de la ejecución de las medidas es la Policía Nacional del Perú, empero, contando, se afirma que el 70\% si cumple en parte y un $30 \%$ no cumple, reinciden.

5. No hay reducción, muy por el contrario, va en aumento debido a muchos factores: Económicos, sociales, culturales, laborales, entre otros. Siendo una buena política el de implantar dentro del currículo escolar un curso netamente sobre violencia, para que desde la niñez se conozca las normas sociales y jurídicas que eviten, prevengan todo tipo de violencia.

Entrevista realizada al Fiscal Provincial:

1. Que muchas de las medidas de protección no van de acorde a la realidad del país, siendo los encargados de la ejecución la Policía Nacional del Perú, debido a que tienen falta de personal, de movilidad y otras necesidades que imposibilitan el cumplimiento de las medidas y que pese a los años de vigencia de la ley aún siguen careciendo, razón por la cual la violencia no disminuye.

2. Generalmente ocurre por miedo al agresor, al que dirán de la familia y por temor a poder quedar desamparadas.

3. La mayoría de casos si, aunque depende mucho del estado en que se encuentre la agravada y los agravantes que son distintos en cada proceso.

4. Los encargados de la ejecución de las medidas de protección es la PNP, pero si existe reincidencia, debido a que el cumplimiento no se da totalmente debido a que el mismo Estado carece de mecanismos y de número de personal.

Claramente no, debido a que en los últimos años se ha visualizado mayor cantidad de denuncias, porque no existe mecanismos que las eviten o prevengan.

\section{Conclusiones}

Tras el desarrollo de la investigación se concluyó lo siguiente:

Existe un alto nivel de eficacia en las medidas de protección pues el Juez del Primer Juzgado de Familia Tarapoto ha cumplido con los plazos señalados para solicitar las medidas de protección 
a favor del agraviado, asimismo se ha efectuado la verificación y control correspondiente por parte de las autoridades competentes para cada una de las medidas dictadas con la finalidad de constatar su cumplimiento inmediato por parte del imputado.

Se pudo conocer que las medidas de protección que más se dictaron frente a los casos de violencia contra la mujer durante los periodos 2017 y 2018 fueron “Tratamiento terapéutico al agresor" en un $46 \%$ para ambos periodos, "Tratamiento psicológico a la víctima" en un 54\% y 46\%, y "Otras medidas de protección requeridas" en un $54 \%$ y $46 \%$.

Respecto a los tipos de violencia contra la mujer denunciadas durante el periodo 2017 y 2018, se reconoce que la violencia física se presentó en un 36\% y 22\%, la violencia psicológica en un $46 \%$ y $41 \%$, la violencia sexual en un $2 \%$ solo durante el periodo 2017 y la violencia económica en un $2 \%$ durante los dos periodos en estudio.

Asimismo, tras el cálculo del coeficiente determinante se determinó que las medidas de protección influyeron en un $80 \%$ frente a los casos de violencia contra la mujer.

\section{Agradecimientos}

Al Abg. Omar Fernández Carranza por la paciencia y el apoyo que brindó para obtener cada una de las sentencias que se analizaron.

Al Especialista Legal del Primer Juzgado de Familia de Tarapoto, Roger Yonel Paredes García, quien me brindó las facilidades para la recopilación de los Expedientes de Violencia contra la Mujer y los Integrantes del grupo Familiar.

\section{Referencias bibliográficas}

Naciones Unidas. (2015). Violencia contra las mujeres.

https://www.ohchr.org/Documents/Issues/Women/WRGS/SexualHealth/INFO_VAW_WE B_SP.pdf

Noticias ONU. (2018). La violencia contra las mujeres: el síntoma de una profunda falta de respeto. https://news.un.org/es/story/2018/11/1446291

Organización de las Naciones Unidas (2017). Violencia contra las mujeres en el Perú. https://ifea.hypotheses.org/1283

Policía Nacional del Perú. (2016). Guía de Procedimientos para la intervención de la Policía Na-cional en el marco de la Ley $N^{\circ} 30364$ "Ley para prevenir, sancionar y erradicar la vio-lencia contra la mujer y los integrantes del grupo familiar" y su Reglamento DS $N^{o}$ 009-2016-MIMP.

Sugobono, N. (2019). Casos de violencia en el Perú. Diario El Comercio. https://elcomercio.pe/somos/eyvi-agreda-ano-muerte-machismo-sigue-cobrando-vidas- 
peru-ecpm-noticia-640395

Torres, S. (2018). Efectividad de las medidas de protección en los procesos de violencia contra la mujer, dictados en los juzgados de familia - Tarapoto, periodo 2017. [Universidad

Cesar Vallejo].

http://repositorio.ucv.edu.pe/bitstream/handle/20.500.12692/40503/Torres_PSC.pdf?seque nce $=1 \&$ is Allowed $=y$

Universidad Ricardo Palma. (2017). Violencia contra la mujer.

http://repositorio.urp.edu.pe/bitstream/handle/urp/1080/Violencia\%20contra\%201a\%20muj er\%20\%281\%29.pdf?sequence=1\&isAllowed=y

Vásquez, E. (2015). Juzgado de familia. https://es.scribd.com/doc/100101837/Juzgado-de-Familia-1-

1

\section{Conflicto de intereses}

No existe conflictos de interés.

\section{Contribuciones de los autores}

La contribución de cada autor se ha realizado de manera coordinada en todo el proceso de elaboración.

Copyright (c) 2021 Esthefany Mondragón Carrasco \& Jose Roberto Siaden Valdivieso

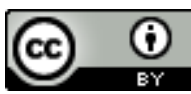

Este texto está protegido por una licencia CreativeCommons 4.0.

Usted es libre para Compartir — copiar y redistribuir el material en cualquier medio o formato- y Adaptar el documento — remezclar, transformar y crear a partir del material— para cualquier propósito, incluso para fines comerciales, siempre que cumpla la condición de:

Atribución: Usted debe dar crédito a la obra original de manera adecuada, proporcionar un enlace a la licencia, e indicar si se han realizado cambios. Puede hacerlo en cualquier forma razonable, pero no de forma tal que sugiera que tiene el apoyo del licenciante o lo recibe por el uso que hace de la obra.

Resumendelicencia - Textocompletodelalicencia 